\title{
Progress in Graphene-Based Electrochemical Biosensors for Cancer Diagnosis
}

\author{
Ruihua Guo* and Wenhui Wu* \\ College of Food Science and Technology, Shanghai Ocean University, Shanghai 201306, China
}

\begin{abstract}
Cancer is one of the leading causes of death worldwide, so early cancer diagnosis is of great significance for successful treatment of cancer. This paper reviews some advances on graphene-based electrochemical biosensors for early cancer diagnosis including electrochemical immunosensors, electrochemical DNA biosensors, and electrochemical cell biosensors.
\end{abstract}

Keywords graphene, graphene oxide, reduced graphene oxide, electrochemical biosensors, cancer biomarkers

\section{Introduction}

Cancer is the second main cause of death in the world. ${ }^{[1]}$ An estimated 14.1 million new cases of cancers and 8.2 million deaths were reported in 2012. ${ }^{[2]}$ Therefore, early cancer diagnosis plays a crucial role for successful treatment of cancer. Some techniques, including polymerase chain reaction-based methods, cytometric methods, fluorescence measurement and single carbon nanotube field effect transistor, have been employed to detect cancer, ${ }^{[3]}$ but they are expensive, time-consuming, fluorescence-labeled or need advanced instrumentation. Electrochemical biosensors possess great potential in cancer diagnosis owing to its simple instrumentation, easy miniaturization, high sensitivity and selectivity.

Graphene is one-atom-thick 2D material owning a honeycomb structure with its $\mathrm{sp}^{2}$ bonded $\mathrm{C}$ atoms. Since its discovery in $2004,{ }^{[4]}$ graphene has attracted much attention for its unique thermal, mechanical and electrical properties. ${ }^{[5-7]}$ It has been utilized widely in many fields such as nanophotonics, ${ }^{[8]}$ nanocomposites, ${ }^{[9]}$ and sensors. ${ }^{[10]}$ Graphene is an ideal electrode material for electrochemical biosensors due to its large surface area $\left(2630 \mathrm{~m}^{2} / \mathrm{g}\right)$, good electrical conductivity $(64 \mathrm{mS} / \mathrm{cm})$, excellent electrochemical activity, and low cost. ${ }^{[11]}$ Graphene oxide (GO) and reduced graphene oxide (rGO) possess several functional groups such as hydroxyl and carboxyl groups, causing good water-solubility, biocompatibility, and electrochemical activity. They are suitable for fabrication of biosensors with high performance.

Graphene-based electrochemical biosensors are an efficient tool for early cancer diagnosis on the basis of non-covalent interaction between graphene and bio- molecules. This paper reviews some advances on graphene-based electrochemical biosensors for cancer diagnosis in details including electrochemical immunosenors, electrochemical DNA biosensors, and electrochemical cell biosensors.

\section{Electrochemical immunosensors}

Cancer biomarkers in blood and tissues are protein molecules related to cancer, so the sensitive detection of cancer biomarkers is of great importance in early cancer diagnosis and clinical treatment. Conventional immunoassay methods suffer from some disadvantages such as hazardous in radioimmunoassay, poor detection limit in enzyme-linked immunosorbent assay, high cost, and so on. Then, immunosensors were developed as an alternative approach. ${ }^{[12]}$ Electrochemical immunosensors attracted tremendous interests on the basis of specific binding of antibody and its corresponding antigen due to their high sensitivity and selectivity. ${ }^{[13]}$

This paper summarizes some advances on graphene-based electrochemical immunosensors will be described according to cancer biomarkers including carcinoembryonie antigen, prostate specific antigen, carbohydrate antigen $15-3$, nuclear matrix protein 22 , vascular endothelial growth factor, $\alpha$-fetoprotein, and latent membrane protein 1 .

\section{Carcinoembryonie antigen}

Carcinoembryonie antigen (CEA) is one of the most important cancer biomarkers associated with colon, lung, ovarian and breast cancer that are responsible for more than half of all cancer deaths each year. ${ }^{[14]}$

Mao group ${ }^{[15]}$ reported on a multi-nanomaterial elec-

\footnotetext{
* E-mail: rhguo@shou.edu.cn,whwu@shou.edu.cn

Received September 16, 2016; accepted October 11, 2016; published online October 12, 2016.
} 
trochemical immunosensor for detection of carcinoembryonie antigen based on a graphene platform combining with magnetic beads (MBs) and enzyme-labeled antibody-gold nanoparticle bioconjugate (Figure 1). MBs coated with capture antibodies $\left(A b_{1}\right)$ were attached to graphene sheets. Gold nanoparticles (AuNPs) were modified with horseradish peroxidase (HRP) and the detection antibody $\left(\mathrm{Ab}_{2}\right)$. Graphene, MBs and AuNPs were utilized to amplify the detection signal. The biosensor is sensitive (LOD $=5 \mathrm{ng} / \mathrm{mL}$ ), and it has potential in the detection of disease markers.

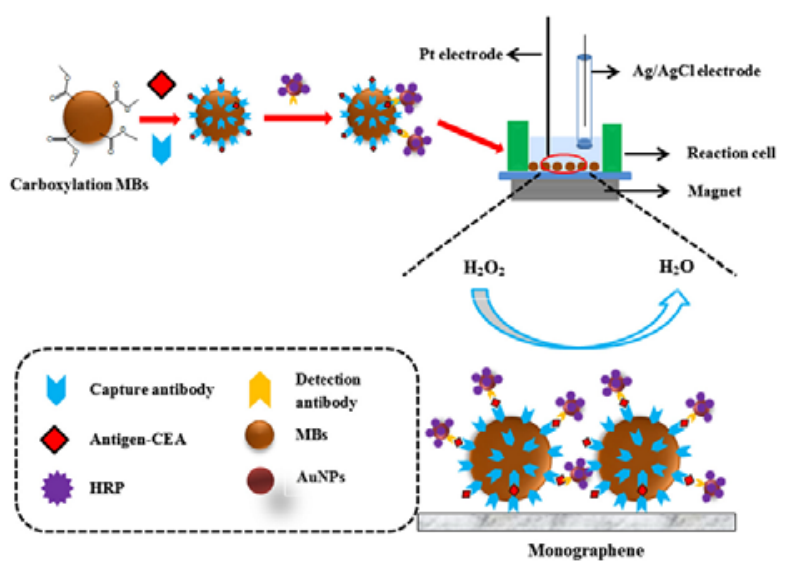

Figure 1 Preparation of the multi-nanomaterial electrochemical biosensor, and carcinoembryonie antigen detection procedure. ${ }^{[15]}$

Yu group ${ }^{[16]}$ developed a novel photoelectrochemical immunosensor for detection of carcinoembryonie antigen using ruthenium tris(bipyridine)-reduced graphene oxide hybrid as the photocurrent signal reporter assembled on rhombic $\mathrm{TiO}_{2}$ nanocrystals driven by visible light. Reduced graphene oxide acts as a solid-state electron mediator and suppresses recombination of photoexcited electron-hole pairs in $\mathrm{Ru}$. The immunosensor showed high sensitivity, high selectivity, excellent stability, and good reproducibility.

Malhotra et al. ${ }^{[17]}$ developed a flexible and highly conducting paper biosensor for detecting carcinoembryonie antigen on the basis of poly(3,4-ethylenedioxythiophene):poly(styrenesulfonate) and reduced graphene oxide, showing sensitivity of $25.8 \mu \mathrm{A} \mathrm{ng}^{-1} \mathrm{~mL}$ $\mathrm{cm}^{-2}$ in the linear range of $2-8 \mathrm{ng} / \mathrm{mL}$ (Figure 2). The conductivity of the conducting paper increases by 300

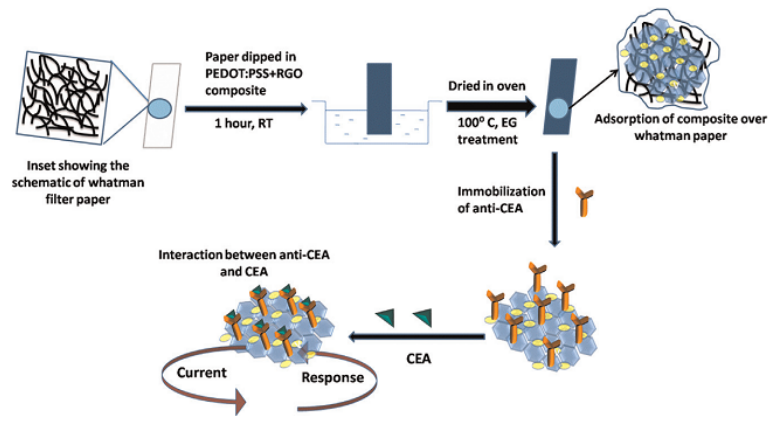

Figure 2 Schematic representation of proposed electroactive paper sensor. ${ }^{[17]}$ times on treatment with ethylene glycol. The incorporation of reduced graphene oxide in the conducting paper film presented excellent electrochemical activity and faster charge transfer kinetics. The flexible, inexpensive and environment friendly conducting paper based biosensor owns immense potential for point-of-care biosensors, flexible electronics and energy storage devices, etc.

Electrochemiluminescence is a special form of chemiluminescence, where light emission is generated by electrochemical reactions. ${ }^{[18]}$ Yuan group ${ }^{[19]}$ fabricated a novel sandwiched luminol electrochemiluminescence immunosensor for detection of carcinoembryonie antigen using $\mathrm{ZnO}$ nanoparticles and glucose oxidase decorated graphene as labels and in situ generated hydrogen peroxide as coreactant, exhibiting excellent sensitivity and stability in the range of $10 \mathrm{pg} / \mathrm{mL}-80$ $\mathrm{ng} / \mathrm{mL}$ and with a detection limit of $3.3 \mathrm{pg} / \mathrm{mL}(\mathrm{S} / \mathrm{N}=3)$. The multiple signal amplification strategy enhanced the chemiluminescence response of the immunosensor, providing a promising potential in detection of tumor markers for clinical diagnostics.

\section{Prostate specific antigen}

Prostate-specific antigen (PSA), a $33 \mathrm{kDa}$ serine protease largely bound to endogenous protease inhibitors in serum, is a biomarker of prostate cancer. ${ }^{[20]}$

Gong group ${ }^{[21]}$ developed an ultrasensitive electrochemical immunosensor employing graphene sheet (GS) for the immobilization of primary antibody $\left(A b_{1}\right)$ and as a tracer to label the secondary antibody $\left(\mathrm{Ab}_{2}\right)$, presenting a wide range of linear response $(0.002-10 \mathrm{ng} / \mathrm{mL})$, low detection limit $(1 \mathrm{pg} / \mathrm{mL})$, good reproducibility, high selectivity and stability (Figure 3 ). It is attributed to the graphene sheet's high surface-to-volume ration and good electrical conductivity. The immunosensor
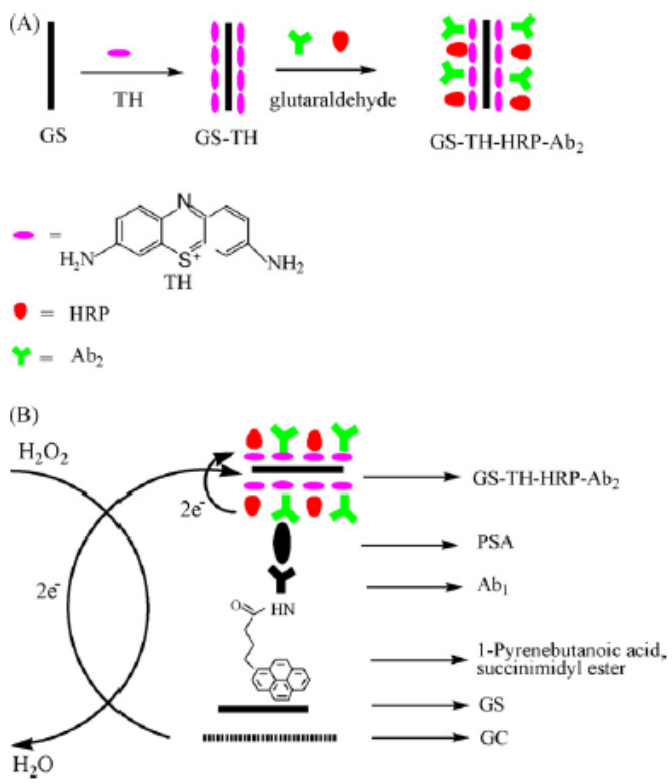

Figure 3 Schematic representation of the preparation of the GS-TH-HRP-Ab ${ }_{2}$ nanostructure (A) and immunosensor (B). ${ }^{[21]}$ 
was uitilized to detect the prostate protein antigen contents in serum samples from patients with satisfactory results. The preparation method is simple and well suitable for high-throughout biomedical sensing and clinical applications. Later, the group ${ }^{[22]}$ prepared a sensitive electrochemical immunosensor for detecting prostate specific antigen using quantum dot functionalized graphene sheets as labels, displaying a wide linear range from 0.005 to $10 \mathrm{ng} / \mathrm{mL}$, low detection limit of $3 \mathrm{pg} / \mathrm{mL}$, good reproducibility and stability.

Yang et al..$^{[23]}$ constructed an ultrasensitive sandwich type electrochemical immunosensor for detection of prostate specific antigen using graphene sheet as a biosensor platform and ferrocene functionalized iron oxide as a label, displaying high sensitivity, wide linear range $(0.01-40 \mathrm{ng} / \mathrm{mL})$, low detection limit $(2 \mathrm{pg} / \mathrm{mL})$, good reproducibility and stability. In addition, the group ${ }^{[24]}$ prepared a label-free amperometric immunosensor for detection of prostate specific antigen combining cobalt hexacyanoferrate nanoparticle with graphene sheet (Figure 4). The specific antibody-antigen immunocomplex caused the decrease of amperometric signal of the electrode. The immunosensor presented a wide linear range of $0.02-2 \mathrm{ng} / \mathrm{mL}$ and a low detection limit of $0.01 \mathrm{ng} / \mathrm{mL}$, providing a simple, economic, sensitive, and specific method for cancer biomarker detection.
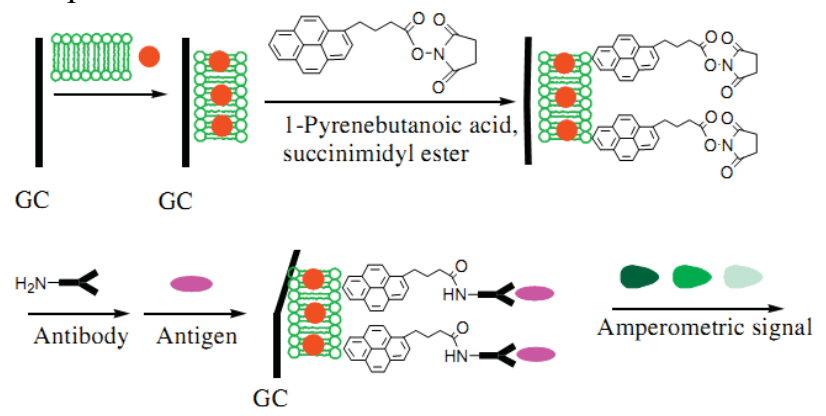

$$
\begin{aligned}
& \text { imomomon } \\
& \text { - }=\mathrm{CoNP}
\end{aligned}
$$

Figure 4 Fabrication steps of the immunosensor. ${ }^{[24]}$

Li group ${ }^{[25]}$ prepared an electrogenerated chemiluminescence sandwich immunosensor for detection of prostate specific antigen on the basis of cathodic electrogenerated chemiluminescence signal with a multiple signal amplification strategy from functionalized graphene and enzyme antibody-conjugated gold nanorods as the sensor platform (Figure 5). The gold nanorods acted as carriers to load more secondary antibodies and glucose oxidase $\left(\mathrm{GO}_{x}\right)$; moreover, the chitosan-functionalized graphene-modified glassy carbon electrode increased the loading of primary antibody $\left(\mathrm{Ab}_{1}\right)$ and catalyzed the cathodic electrogenerated chemiluminescence reaction. The immunosensor presented high sensitivity and specificity, a wide linear range of $10 \mathrm{pg} / \mathrm{mL}$ $-8 \mathrm{ng} / \mathrm{mL}$, low detection limit $8 \mathrm{pg} / \mathrm{mL}(\mathrm{S} / \mathrm{N}=3)$, excellent stability and reproducibility. It has potential in the point-of-care diagnostics application of clinical

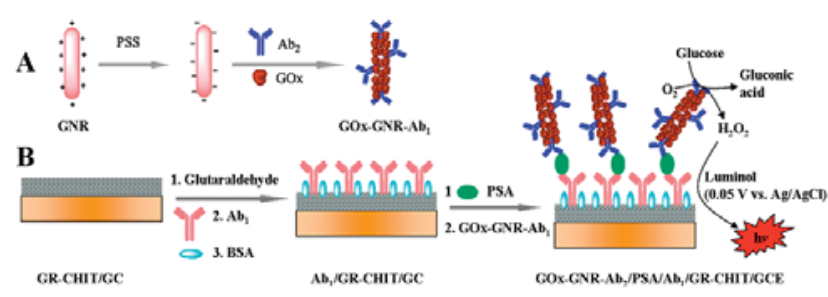

Figure 5 (A) Modification procedure of gold nanorods and (B) electrogenerated chemiluminescence immunoassay of prostate specific antigen with multiple amplification strategy based on a graphene composite modified electrode. ${ }^{[25]}$

screening of cancer biomarkers.

$\mathrm{Yu}$ group ${ }^{[26]}$ designed a novel electrochemiluminescence immunosensor for detection of prostate specific antigen using biofunctionalized magnetic graphene nanosheets graphene@ $\mathrm{Fe}_{3} \mathrm{O}_{4}$ as immunosensing probes and $\mathrm{CdTe}$ quantum dots coated silica nanospheres as signal amplification labels. Graphene $@ \mathrm{Fe}_{3} \mathrm{O}_{4}$ not only promoted washing after synthesis with good biocompatibility, but also facilitated the electronic transfer and enhanced the detection signals. The immunosensor had a wide linear range of $0.003-50 \mathrm{ng} / \mathrm{mL}$ and a low detection limit of $0.72 \mathrm{pg} / \mathrm{mL}$. The strategy is suitable for high-throughput biomedical sensing and application to other areas.

Srivastava group $^{[27]}$ developed an electrochemical immunosensor for ultrasensitive detection of the prostate-specific antigen employing a palladium nanoparticle decorated-reduced graphene oxide. The immunosensor exhibited high sensitivity of $28.96 \mu \mathrm{A} \mathrm{mL}$ $\mathrm{ng}^{-1} \mathrm{~cm}^{-2}$, a wide linear range of $0.01-12.5 \mathrm{ng} / \mathrm{mL}$, good reproducibility, and long term stability with acceptable accuracy in human serum samples. It is attributed to the synergistically improved conductivity and the large surface area with enough functional groups in the palladium nanoparticle decorated-reduced graphene oxide nanostructure.

\section{Carbohydrate antigen 15-3}

As a cancer biomarker, carbohydrate antigen 15-3 (CA 15-3) plays a great role in the diagnosis of breast cancer. $^{[28]}$

$\mathrm{Li}$ group $^{[29]}$ reported on a novel electrochemical immunosensor for label-free detection of carbohydrate antigen 15-3 with $N$-doped graphene-modified electrode (Figure 6). The immunosensor worked well over a wide linear range of $0.1-20 \mathrm{U} / \mathrm{mL}$ with a low detection limit of $0.012 \mathrm{U} / \mathrm{mL}$. The highly conductive $N$-doped graphene resulted in much increased sensitivity for the significant promotion for electron transfer in the sensing system. The strategy provides a promising approach for clinical research and diagnostic applications.

Rahman group ${ }^{[30]}$ constructed an ultrasensitive electrochemical nanostructured immunosensor for carbohydrate antigen 15-3 using non-covalent functiona lized graphene oxides/Py-COOH as a sensor probe and 


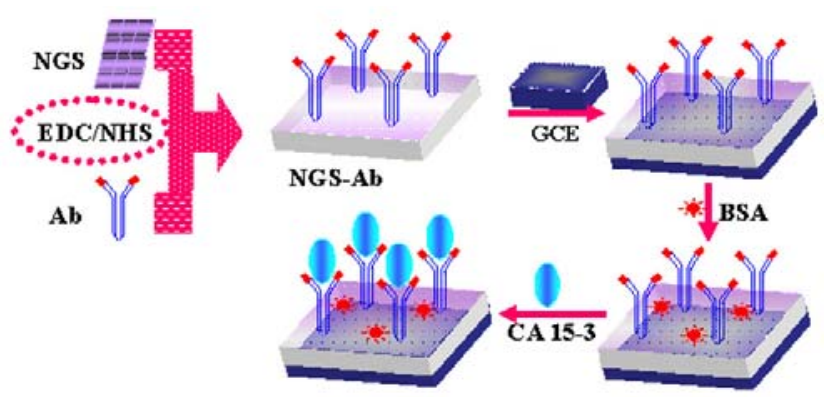

Figure 6 Schematic presentation of the fabrication of the immunosensor. ${ }^{[29]}$

multiwalled carbon nanotube-supported numerous ferritin as labels. The non-covalent functionalization of graphene oxide offered enough carboxylic acid groups, which allowed the covalent immobilization of a monoclonal anti-carcinoembryonie antigen antibody. The immunosensor exhibited excellent selectivity, low detection limit, and better stability in human serum samples. It suggested that the immunosensor has potential in proteomic research and diagnostics.

Deng et $a l .{ }^{[31]}$ prepared Au nanoparticles/ferroceneelectrochemically reduced graphene oxide, which was employed for the immobilization platform for antibodies and signal probes to fabricate an immunosensor for the sensitive detection of breast cancer biomarker carbohydrate antigen 15-3 (Figure 7). The immunosensor presented significant sensitivity and a wide linear range, offering a potential approach for clinical research and diagnostic applications.

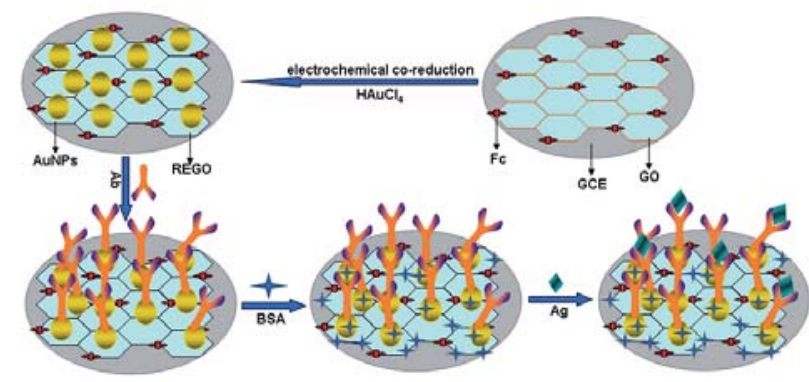

Figure 7 The fabrication of the immunosensor and the immunoassay procedure. ${ }^{[31]}$

\section{Nuclear matrix protein 22}

Nuclear matrix protein 22 (NMP22) is a typical biomarker of bladder cancer. It is significant to detect nuclear matrix protein 22 in the early diagnosis of bladder cancer.

Wei et al. ${ }^{[32]}$ prepared a simple electrochemical immunosensor for detection of nuclear matrix protein 22 using reduced graphene oxide-tetraethylene pentamine (TEPA) and trimetallic AuPdPt nanoparticles (AuPdPt NPs), where reduced graphene oxide-tetra-ethylene pentamine was the ideal material for signal amplification and AuPdPt nanoparticles immobilization for its excellent conductivity and large surface area (Figure 8).
The immunosensor exhibited low detection limit (0.01 $\mathrm{U} / \mathrm{mL})$, a wide linear range $(0.040-20 \mathrm{U} / \mathrm{mL})$, high sensitivity, and excellent selectivity. It was utilized to test real urine samples with satisfactory results. The proposed strategy could also be applied to detect other biomarkers.

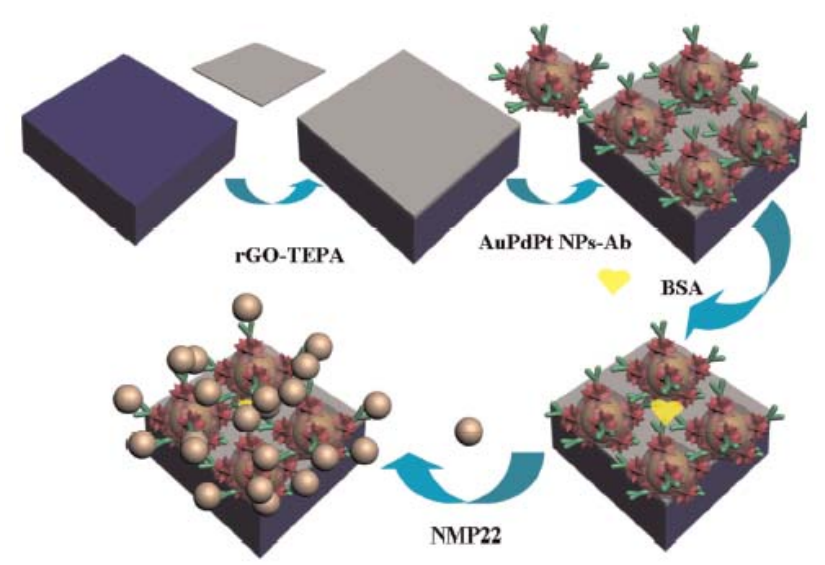

Figure 8 Schematic representation of the preparation of the immunosensor. ${ }^{[32]}$

\section{Vascular endothelial growth factor}

Vascular endothelial growth factor is involved in many human cancers, such as brain tumors, lung cancer, breast cancer, gastrointestinal cancer and urinary tract tumors. ${ }^{[33]}$

Ma et al. ${ }^{[34]}$ proposed a reusable biosensor based on a magnetic graphene oxide-modified $\mathrm{Au}$ electrode to detect vascular endothelial growth factor in human plasma for cancer diagnosis, where avastin is employed as the specific biorecognition element and magnetic graphene oxide is utilized as the carrier for avastin loading. The biosensor possessed a wide linear range of $31.25-2000 \mathrm{pg} / \mathrm{mL}$, low limit of detection (31.25 $\mathrm{pg} / \mathrm{mL})$, and good stability $(\mathrm{RSD}=2.36 \%, n=50)$. It presents the groundwork for the employment of magnetic graphene oxide and avastin in medical diagnostics and biotechnology.

\section{$\alpha$-Fetoprotein}

$\alpha$-Fetoprotein (AFP) is a glycoprotein involved in hepatocellular carcinoma.

Lin group $^{[35]}$ developed a novel electrochemical immunosensor for detection of $\alpha$-fetoprotein using a graphene sheet sensor platform and functionalized carbon nanospheres (CNS) labeled with horseradish peroxidase-secondary antibodies, presenting a 7-fold increase in detection signal in comparison with the immunosensor without graphene modification and carbon nanospheres labeling (Figure 9). The method could respond to $0.02 \mathrm{ng} / \mathrm{mL} \alpha$-fetoprotein with a linear calibration range from 0.05 to $6 \mathrm{ng} / \mathrm{mL}$ and provide a promising platform for clinical screening of cancer biomarkers and point-of-care diagnostics. 


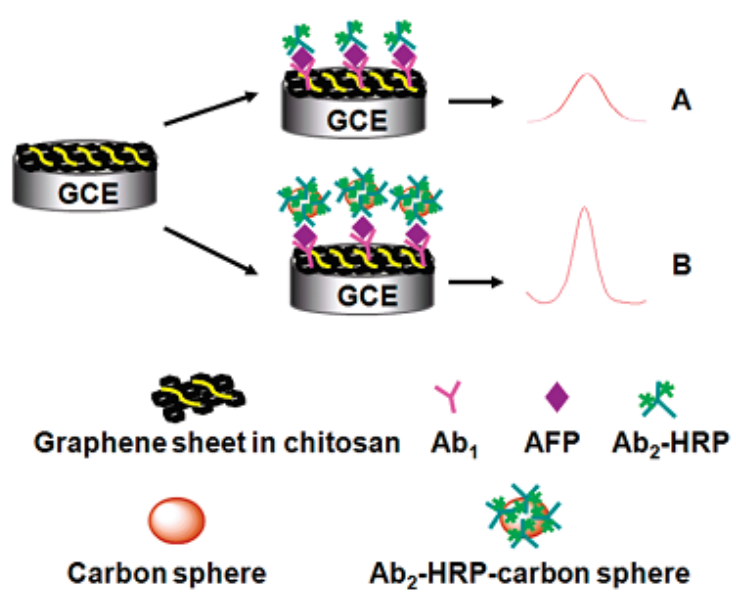

Figure 9 Schematic illustration of detection principles of $\mathrm{HRP}-\mathrm{Ab}_{2} / \mathrm{AFP} / \mathrm{Ab}_{1} / \mathrm{GS}-\mathrm{CHI} / \mathrm{SPCE}$ (A) and HRP-Ab 2 -CNSs/ $\mathrm{AFP} / \mathrm{Ab}_{1} / \mathrm{GS}-\mathrm{CHI} / \mathrm{SPCE}$ (B) using a signal amplification strategy at the graphene sheets sensor platform. ${ }^{[35]}$

Xia group $^{[36]}$ fabricated a solid-state electrochemiluminescent immunosensor based on ruthenium(II) complex/3,4,9,10-perylenetetracarboxylic acid /graphene nanocomposites for detection of $\alpha$-fetoprotein, presenting an extremely sensitive response to $\alpha$ -fetoprotein in a linear range of $5 \mathrm{pg} / \mathrm{mL}-10 \mathrm{ng} / \mathrm{mL}$ with a detection limit of $0.2 \mathrm{pg} / \mathrm{mL}$. The method is a promising technique for biomolecular detection.

\section{Latent membrane protein 1}

Latent membrane protein 1 (LMP-1) is a biomarker related to nasopharyngeal carcinoma.

Xie et al. ${ }^{[37]}$ constructed an electrochemical sandwich immunosensor for determination of latent membrane protein 1, where the capture antibody was immobilized on a graphene sheet/carboxylated multiwalled carbon nanotube composite (MWCNT) in a chitosan matrix and the detection antibody was fixed on a horseradish peroxidase/Pd@Pt-MWCNT composite (Figure 10). Following exposure to the antigen (LMP-1), an amplified signal was observed in differential pulse voltammetry in the presence of added $\mathrm{H}_{2} \mathrm{O}_{2}$. The immunosensor owned a wide linear range from 0.01 to

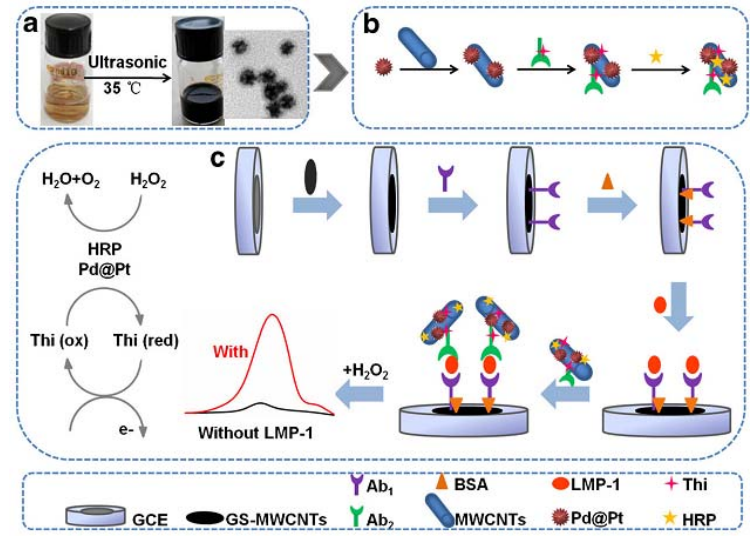

Figure 10 (a) Photographs of solutions before and after the reaction, (b) The preparation of $\mathrm{Ab}_{2} / \mathrm{Thi} / \mathrm{HRP} / \mathrm{Pd} @ \mathrm{Pt}-\mathrm{MWCNTs}$ and (c) The fabricating procedure for LMP-1 immunosensor. ${ }^{[37]}$
$40 \mathrm{ng} / \mathrm{mL}$ and low detection limit of $0.62 \mathrm{pg} / \mathrm{mL}(\mathrm{S} / \mathrm{N}=$ 3 ), providing a promising tool for an early diagnosis of nasopharyngeal carcinoma.

\section{Multiple biomarkers}

The determination of a single cancer biomarker suffers from poor specificity between biomarkers and cancers, ${ }^{[38]}$ so it is significant to develop simultaneous assay of multiple cancer biomarkers in clinical diagnosis.

Hui group ${ }^{[39]}$ reported firstly on a paper-based microfluidic electrochemical immunosensor integrated with nanobioprobes onto graphene film for ultrasensitive multiplexed detection of $\alpha$-fetoprotein, carcinoembryonic antigen, cancer antigen 125, and carbohydrate antigen, where horseradish peroxidase and antibody coimmobilized silica nanoparticles and graphene were employed to achieve dual signal amplification (Figure 11). The immunosensor exhibited a detection limit at the sub $\mathrm{pg} / \mathrm{mL}$ level, indicating effective strategies of signal amplification for ultrasensitive detection of cancer biomarkers.

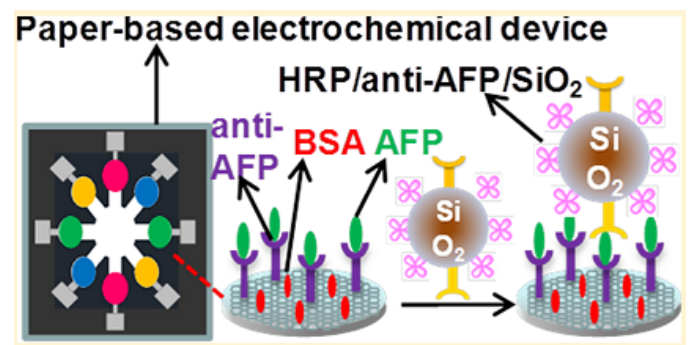

Figure 11 Paper-based microfluidic electrochemical immunosensor integrated with nanobioprobes onto graphene film. ${ }^{[39]}$

Hong group ${ }^{[40]}$ developed a novel electrochemical immunosensor for simultaneous detection of $\alpha$-fetoprotein and carcinoembryonic antigen using $\mathrm{Cu}_{2} \mathrm{O}-$ graphene oxide- $\beta$-cyclodextrin and $\beta$-cyclodextringraphene oxide-ferrocenecarboxylic acid as a distinguishable signal probe, and graphene oxide-gold nanoparticles as a sensor platform (Figure 12). The linear ranges were from 0.001 to $80 \mathrm{ng} / \mathrm{mL}$ for $\alpha$-fetoprotein and carcinoembryonic antigen with a detection limit of

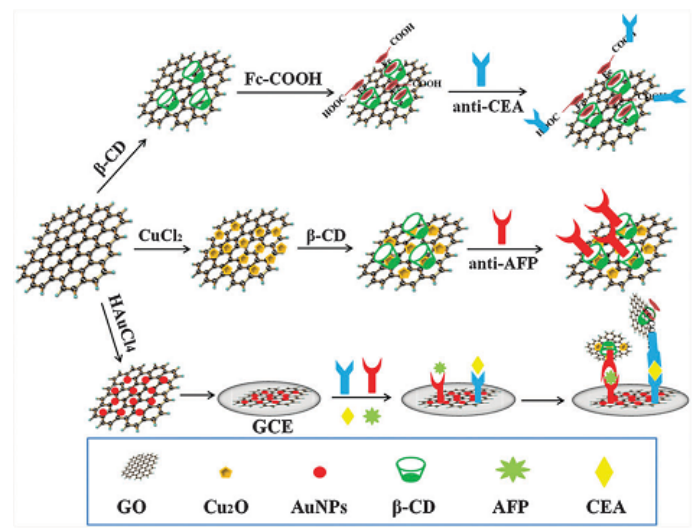

Figure 12 The schematic of the sandwich-type electrochemical immunosensor. ${ }^{[40]}$ 
$0.0002 \mathrm{ng} / \mathrm{mL}$ for $\alpha$-fetoprotein and $0.0001 \mathrm{ng} / \mathrm{mL}$ for carcinoembryonic antigen. The immunosensor possessed acceptable stability, high sensitivity, a wide linear range and a low detection limit, showing great potential for simultaneous detection of multianalytes in clinical diagnosis.

Besides this, Ma et al. ${ }^{[41]}$ fabricated a sandwich-format electrochemical immunosensor for simultaneous determination of carcinoembryonic antigen and $\alpha$-fetoprotein on the basis of biofunctional carboxyl graphene nanosheets. Wei group ${ }^{[42]}$ prepared a novel and highly sensitive electrochemical immunosensor for simultaneous detection of carcinoembryonic antigen and squamous cell carcinoma antigen for diagnosis of cervical cancer using reduced graphene oxide-tetraethylene pentamine as electrode materials and distinguishable redox probes as labels.

\section{Electrochemical DNA biosensors}

Electrochemical DNA sensors based on electroactive DNA bases are attractive in early cancer diagnosis owing to their simplicity, low cost, and high sensitivity and miniaturization.

Sandhyarani et $a l^{[43]}$ developed a graphene-based electrochemical DNA biosensor for detection of breast cancer-related BRCA1 gene DNA (target DNA as DNA-t) using gold nanoparticle as an electrochemical label. The capture probe DNA-c was immobilized on graphene-modified glassy carbon electrode. One-half of the DNA-t hybridized to the immobilized DNA-c and the other half of DNA-t to the reporter probe DNA-r conjugated with gold nanoparticles (Figure 13). Electrochemical oxidation of gold nanoparticle was monitored using cyclic voltammetry to detect the concentration of DNA-t. The biosensor was stable, reproducible and sensitive; moreover, it could detect up to 1 femtomolar BRCA1 gene (5.896 femtogram $/ \mathrm{mL})$. Later, the group $^{[44]}$ employed reduced graphene oxide-yttria nanocomposite as an electrochemical genosensor platform for ultrahigh sensitive detection of breast cancer 1 gene for the first time, which presented a linear range of 10 attomolar to 1 nanomolar and a detection limit of 5.95 attomolar.

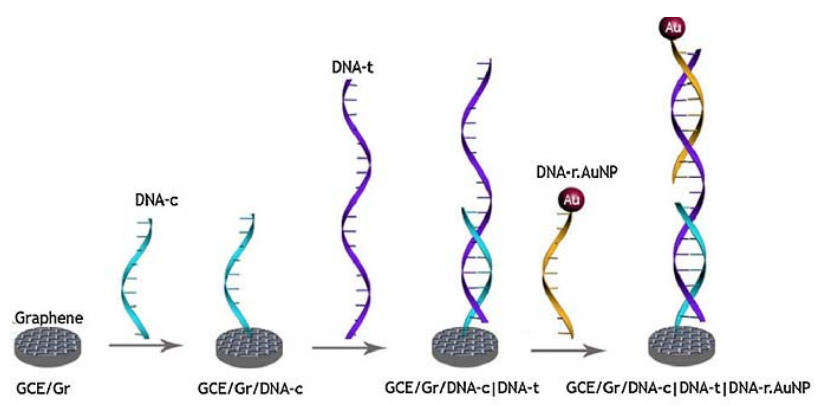

Figure 13 The schematic representation of the various stages of sensor fabrication. ${ }^{[43]}$

Pingarrón et al. ${ }^{[45]}$ developed firstly novel disposable electrochemical DNA biosensors for detection of a target DNA sequence on the p53 tumor suppressor gene utilizing reduced graphene oxide-carboxymethylcellulose hybrid nanostructured scaffolds and DNA hairpin probes of different length. Screen-printed carbon electrodes were modified with reduced graphene oxidecarboxymethylcellulose as platforms for covalent immobilization of two different selective hairpin-forming capture probes. The DNA biosensors can discriminate single nucleotide polymorphism in cDNAs from human breast cancer cell lines and act as new diagnosis tools in clinical analysis.

\section{Electrochemical cell biosensors}

Electrochemical cell biosensors attract much interest because of their simplicity and sensitivity.

Chen et al. ${ }^{[46]}$ developed an electrochemical impedance spectroscopy biosensor for label-free detection of live cancer cells by the self-assembly of a new synthesized galactosyl anthraquinone dye (GalAQ) on the surface of a graphene electrode (Figure 14). Live cancer cells could be captured on the basis of selective sugar-receptor recognitions, producing a sensitive impedance signal. Knockdown of the receptor resulted in a sharp decrease of the impedance signal, meaning that the biosensor is suitable for the direct live cell capture based on ligand-receptor recognitions.
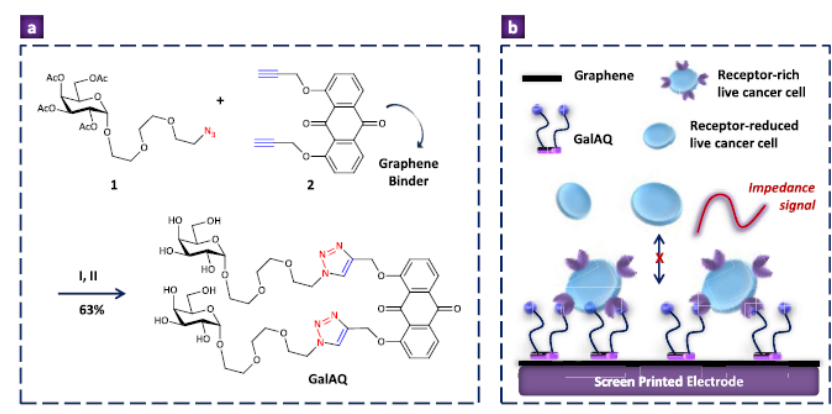

Figure 14 (a) Synthesis of GalAQ. Reagents and conditions: (I) $\mathrm{CuSO}_{4} \cdot 5 \mathrm{H}_{2} \mathrm{O}$, sodium ascorbate, $\mathrm{CH}_{2} \mathrm{Cl}_{2} / \mathrm{H}_{2} \mathrm{O}$; (II), $\mathrm{Et}_{3} \mathrm{~N}$, $\mathrm{MeOH} / \mathrm{H}_{2} \mathrm{O}$. (b) Cartoon depicting the label-free impedance detection of receptor-rich live cancer cells. ${ }^{[46]}$

$\mathrm{Yu}$ group $^{[47]}$ constructed a sensitive photoelectrochemical biosensor using $\mathrm{ZnO}$ /graphene and $\mathrm{S6}$ aptamers for detection of SK-BR-3 breast cancer cells based on a disposable indiium tin oxide device (Figure 15). The biosensor exhibited a low detection limit of 58 cells $/ \mathrm{mL}$ and a wide linear range of $1 \times 10^{2}-1 \times 10^{6}$ cells $/ \mathrm{mL}$. The method is sensitive, stable and low cytotoxic. Therefore, it is suitable for early and accurate detection of cancer cells.

Bala group ${ }^{[48]}$ fabricated a novel amperometric biosensor based on gold nanoparticles anchored on reduced graphene oxide and $L$-lactate dehydrogenase for sensing $L$-lactate tumor biomarker (Figure 16). The biosensor showed a wide linear range of $10 \mathrm{mM}-5 \mathrm{mM}$, a good specific sensitivity of $154 \mathrm{~mA} /\left(\mathrm{mM} \mathrm{cm}^{2}\right)$, and low de- 


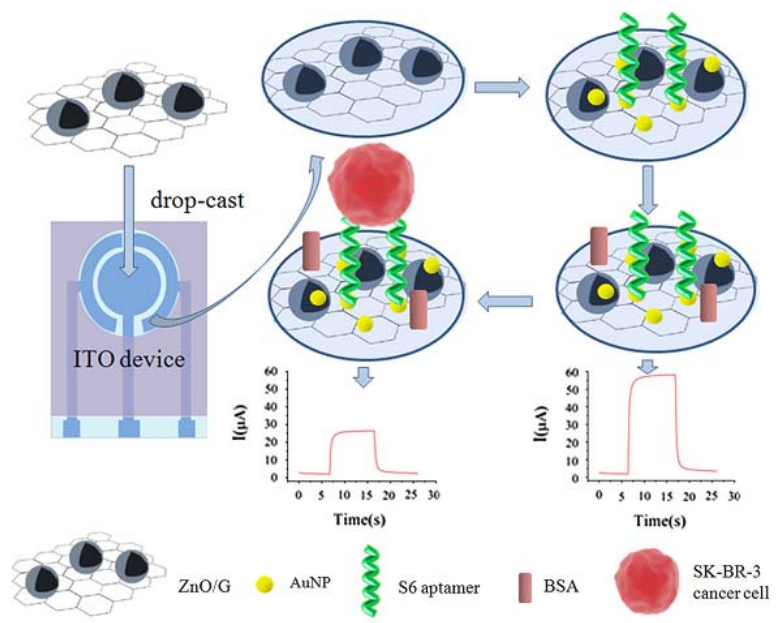

Figure 15 Schematic representation of the fabrication of the photoelectrochemical cell sensor based on S6 aptamers-AuNPs dotted $\mathrm{ZnO} /$ graphene modified indium tin oxide working electrode. $^{[47]}$

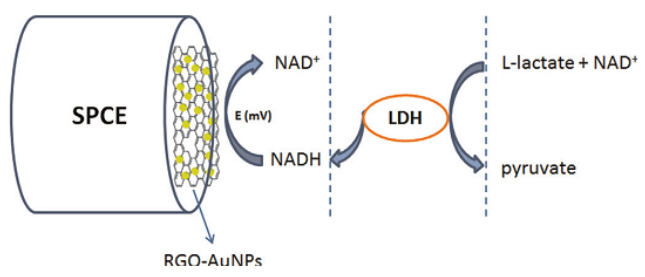

Figure 16 Schematic representation of working principle of the LDH/RGO-AuNPs/SPCE biosensor. ${ }^{[48]}$

tection limit of $0.13 \mathrm{mM}$. The biosenor can be employed as electrochemical device for detection of $L$-lactate as a viable early cancer biomarker.

In addition, He et al.$^{[49]}$ proposed a novel electrochemical impedance biosensor for detecting leukemia K562 cells based on a new biocompatible film combining of graphene oxide and poly- $L$-lysine. Qu group ${ }^{[57]}$ reported on an electrochemical biosensor for selective label-free detection of cancer cells based on the first clinical trial II used aptamer AS1411 and functionalized graphene. Castillo-León et al. ${ }^{[50]}$ prepared a new electrochemical biosensor utilizing graphene electrode modified with a new conjugate of peptide nanotubes and folic acid for detection of human cervical cancer cells over-expressing folate receptors.

\section{Conclusions and Prospective}

Three electrochemical cancer biosensors on the basis of graphene and its derivatives were described including electrochemical immunosensors, electrochemical DNA biosensors, and electrochemical cell biosensors. Graphene and its derivatives own great potential in electrochemical cancer biosensors for their unique structures and properties. Graphene combines with metal nanoparticles, conductive polymers, carbon nanotubes, room temperature ion liquids to form new hybrid materials, which will be helpful for improving the sensitivity of biosensors. However, based-graphene electrochemical biosensors face health concerns on toxicity of graphene materials. ${ }^{[51,52]}$ In addition, researchers require development of new synthetic methods to prepare scalable, controllable and reproducible graphene. It is appealing to fabricate graphene-based electrochemical biosensors capable of clinical practical application for early cancer diagnosis.

\section{References}

[1] Siegel, R.; Naishadham, D.; Jemal, A. Ca-Cancer J. Clin. 2012, 62, 10.

[2] Cancer, I. Af. R. o., World Cancer Factsheet, World Health Organization, 2012, http://www.cancerresearchuk.org.

[3] (a) Paterlini-Brechot, P.; Benali-Furet, N. L. Cancer Lett. 2007, 253, 180e204; (b) Kang, C.; Chang, C.; Chang, T.; Liao, L.; Lou, P.; Xie, W.; Yeung, E. S. Analyst 2007, 232, 745e9; (c) Teker, K. Mater. Sci. Eng. B 2008, 153, 83e7.

[4] Novoselov, K. S.; Geim, A. K.; Morozov, S. V.; Jiang, D.; Zhang, Y.; Dubonos, S. V.; Grigorieva, I. V.; Firsov, A. A. Science 2004, $306,666$.

[5] Geim, A. K.; Novoselov, K. S. Nat. Mater. 2007, 6, 183.

[6] Wang, D. W.; Li, F.; Wu, Z. S.; Ren W.; Cheng, H. M. Electrochem. Commun. 2009, 11, 1729.

[7] Li, X. L.; Zhang, G. Y.; Bai, X. D.; Sun, X. M.; Wang, X. R.; Wang, E.; Dai, H. J. Nat. Nanotechnol. 2008, 3, 538.

[8] Xu, Y. F.; Liu, Z. B.; Zhang, X. L.; Wang, Y.; Tian, J. G.; Huang, Y.; Ma, Y. F.; Zhang, X. Y.; Chen, Y. S. A. Adv. Mater. 2009, 21, 1275.

[9] Watcharotone, S.; Dikin, D. A.; Stankovich, S.; Piner, R.; Jung, I.; Dommett, G. H. B.; Evmenenko, G.; Wu, S. E.; Chen, S. F.; Liu, C. P.; Neugen, S. T.; Ruoff, R. S. Nano Lett. 2007, 7, 1888.

[10] Shao, Y. Y.; Wang, Y.; Wu, H.; Liu, J.; Aksay, I. A.; Lin, Y. H. Electroanalysis 2010, 22, 1027.

[11] (a) Stoller, M. D.; Park, S.; Zhu, Y.; An, J. Nano Lett. 2008, 8, 3498.; (b) Liu, C.; Alwarappan, S.; Chen, Z.; Kong, X.; Li, C. Z. Biosens. Bioelectron. 2010, 25, 1829.; (c) Brownson, D. A. C.; Banks, C. E. Analyst 2010, 135, 2768.

[12] Turner, A. P. F. Nat. Biotechnol. 1997, 15, 421.

[13] Prabhukar, S.; Alwarappan, S.; Liu, G.; Li, C.-Z. Biosens. Bioelectron. 2009, 24, 3524.

[14] (a) Kulpa, J.; Wójcik, E.; Reinfuss, M.; Kołodziejski, L. Clin. Chem. 2002, 48, 1931; (b) Myers, R. E.; Sutherland, D. J.; Meakin, J. W.; Kellen, J. A.; Malkin, D. G.; Malkin, A. Cancer 1978, 42, S1520; (c) Pepe, M. S.; Etzioni, R.; Feng, Z.; Potter, J. D.; Thompson, M. L.; Thornquist, M.; Winget, M.; Yasui, Y. J. Natl. Cancer Inst. 2001, 93, 1054; (d) Wanebo, H. J.; Rao, B.; Pinsky, C. M.; Hoffman, R. G.; Stearns, M.; Schwartz, M. K.; Oettgen, H. F. N. Engl. J. Med. 1978, 299, 448.

[15] Jin, B.; Wang, P.; Mao, H.; Hu, B.; Zhang, H.; Cheng, Z.; Wu, Z.; Bian, X.; Jia, C.; Jing, F.; Jin, Q.; Zhao, J. Biosens. Bioelectron. 2014, 55, 464.

[16] Ge, L.; Wang, Y.; Yang, H.; Yang, P.; Cheng, X.; Yan, M.; Yu, J. Anal. Chim. Acta 2014, 828, 27.

[17] Kumar, S.; Kumar, S.; Srivastava, S.; Yadav, B. K.; Lee, S. H.; Sharma, J. G.; Doval, D. C.; Malhotra, B. D. Biosens. Bioelectron. 2015, 73, 114.

[18] Dong, Y.; Cui, H.; Xu, Y. Langmuir 2007, 23, 523.

[19] Cheng, Y.; Yuan, R.; Chai, Y.; Niu, H.; Cao, Y.; Liu, H.; Bai, L.; Yuan, Y. Anal. Chim. Acta 2012, 745, 137.

[20] (a) Lilja, H.; Ulmert, D.; Vickers, A. J. Nat. Rev. Cancer 2008, 8, 268; (b) Landis, S. H.; Murray, T.; Bolden, S.; Wingo, P. A. Ca-Cancer J. Clin. 1999, 49, 8; (c) Fernández-Sánchez, C.; McNeil, C. J.; Rawson, K.; Nilsson, O. Anal. Chem. 2004, 76, 5649; (d) Fern 
ández-Sánchez, C.; Gallardo-Soto, A. M.; Rawson, K.; Nilsson, O.; McNeil, C. J. Electrochem. Commun. 2004, 6, 138

[21] Yang, M.; Javadi, A.; Li, H.; Gong, S. Biosens. Bioelectron. 2010, $26,560$.

[22] Yang, M.; Javadi, A.; Gong, S. Sens. Actuator B 2011, 155, 357.

[23] Li, H.; Wei, Q.; He, J.; Li, T.; Zhao, Y.; Cai, Y.; Du, B.; Qian, Z.; Yang, M. Biosens. Bioeletron. 2011, 26, 3590.

[24] Li, T.; Yang, M.; Li, H. J. Electroanal. Chem. 2011, 655, 50.

[25] Xu, S.; Liu, Y.; Wang, T.; Li, J. Anal. Chem. 2011, 83, 3817.

[26] Liu, F.; Zhang, Y.; Ge, S.; Lu, J.; Yu, J.; Song, X.; Liu, S. Talanta 2012, 99, 512

[27] Kumar, V.; Srivastava, S.; Umrao, S.; Kumar, R.; Nath, G.; Sumana, G.; Saxena, P. S.; Srivastava, A. RSC Adv. 2014, 4, 2267.

[28] Duffy, M. J.; Evoy, D.; McDermott, E. W. Clin. Chim. Acta 2010, 411,1869

[29] Li, H.; He, J.; Li, S.; Turner, A. P. F. Biosens. Bioelectron. 2013, 43, 25.

[30] Akter, R.; Jeong, B.; Choi, J. S.; Rahman, M. A. Biosens. Bioelectron. 2016, 80, 123.

[31] Li, C.; Qiu, X.; Deng, K.; Hou, Z. Anal. Methods 2014, 6, 9078.

[32] Ma, H.; Zhang, X.; Li, X.; Li, R.; Du, B.; Wei, Q. Talanta 2015, 143, 77.

[33] Ferrara, N.; Gerber, H. P.; LeCouter, J. Nat. Med. 2003, 9, 669.

[34] Lin, C. W.; Wei, K. C.; Liao, S. S.; Huang, C. Y.; Sun, C. L.; Wu, P. J.; Lu, Y. J.; Yang, H. W.; Ma, C. C. M. Biosens. Bioelectron. 2015, $67,431$.

[35] Du, D.; Zou, Z.; Shin, Y.; Wang, J.; Wu, H.; Engelhard, M. H.; Liu, J.; Aksay, I. A.; Lin, Y. Anal. Chem. 2010, 82, 2989.

[36] Xiao, F. N.; Wang, M.; Wang, F. B.; Xia, X. H. Small 2014, 10, 706.

[37] Zhang, X.; Zhou, D.; Sheng, S.; Yang, J.; Chen, X.; Xie, G.; Xiang,
H. Microchim. Acta 2016, 183, 2055

[38] Chikkaveeraiah, B.V.; Bhirde, A. A.; Morgan, N. Y.; Eden, H. S.; Chen, X. Y. ACS Nano 2012, 6, 6541.

[39] Wu, Y.; Xue, P.; Kang, Y.; Hui, K. M. Anal. Chem. 2013, 85, 8661.

[40] Feng, T.; Qiao, X.; Wang, H.; Sun, Z.; Qi, Y.; Hong, C. J. Mater. Chem. B 2016, 4, 990.

[41] Chen, X.; Jia, X.; Han, J.; Ma, J.; Ma, Z. Biosens. Bioelectron. 2013, $50,356$.

[42] Wu, D.; Guo, A.; Guo, Z.; Xie, L.; Wei, Q.; Du, B. Biosens. Bioelectron. 2014, 54, 634

[43] Rasheed, P. A.; Sandhyarani, N. Sens. Actuator B 2014, 204, 777.

[44] Rasheed, P. A.; Radhakrishnan, T.; Shihabudeen, P. K.; Sandhyarani, N. Biosens. Bioelectron. 2016, 83, 361.

[45] Esteban-Fernandez de Avila, B.; Araque, E.; Campuzano, S.; Pedrero, M.; Dalkiran, B.; Barderas, R.; Villalonga, R.; Kilic, E.; Pingarron, J. M. Anal. Chem. 2015, 87, 2290.

[46] Cui, L.; Zhu, B. W.; Qu, S.; He, X. P.; Chen, G. R. Dyes Pigment. 2015, 121, 312.

[47] Liu, F.; Zhang, Y.; Yu, J.; Wang, S.; Ge, S.; Song, X. Biosens. Bioelectron. 2014, 51, 413.

[48] Azzouzi, S.; Rotariu, L.; Benito, A. M.; Maser, W. K.; Ali, M. B.; Bala, C. Biosens. Bioelectron. 2015, 69, 280.

[49] Zhang, D.; Zhang, Y.; Zheng, L.; Zhan, Y.; He, L. Biosens. Bioelectron. 2013, 42, 112.

[50] Castillo, J. J.; Sendsen, W. E.; Rozlosnik, N.; Escobar, P.; Martí nez, F.; Castillo-León, J. Analyst 2013, 138, 1026.

[51] Seabra, A. B.; Paula, A. J.; de Lima, R.; Alves, O. L.; Duran, N. Chem. Res. Toxicol. 2014, 27, 159.

[52] Ma, Y.; Shen, H.; Tu, X.; Zhang, Z. Nanomedicine 2014, 9, 1565. 